Article

\title{
Low-Temperature Hydrothermal Treatment Surface Functionalization of the Ultrafine-Grained TiMo Alloys for Medical Applications
}

\author{
Daria Piechowiak (D, Andrzej Miklaszewski * (D) and Mieczysław Jurczyk \\ Institute of Materials Science and Engineering, Poznan University of Technology, Pl. M. Sklodowskiej-Curie 5, \\ 60-965 Poznan, Poland; daria.a.piechowiak@doctorate.put.poznan.pl (D.P.); \\ mieczyslaw.jurczyk@put.poznan.pl (M.J.) \\ * Correspondence: andrzej.miklaszewski@put.poznan.pl
}

Received: 27 November 2020; Accepted: 15 December 2020; Published: 17 December 2020

check for updates

\begin{abstract}
Hydroxyapatite (HAp) is the most widely used material for bio coating. The functional layer can be produced by many methods, however, the most perspective by its utility, easy to scale up, and simplicity aspects remains a hydrothermal treatment approach. In this work, an HAp coating was produced by low-temperature hydrothermal treatment on the ultrafine-grain beta Ti-xMo $(x=23$, 27, $35 \mathrm{wt.} \%$ ) alloys. The proposed surface treatment procedure combines acid etching, alkaline treatment (AT), and finally hydrothermal treatment (HT). The uniqueness of the approach relies on the recognition of the influence of the molar concentration of $\mathrm{NaOH}(5 \mathrm{M}, 7 \mathrm{M}, 10 \mathrm{M}, 12 \mathrm{M})$ during the alkaline treatment on the growth of hydroxyapatite crystals. Obtained and modified specimens were examined structurally and microstructurally at every stage of the process. The results show that the layer after AT consist of titanium oxide and phases based on sodium with various phase relations dependent on $\mathrm{NaOH}$ concentration and base composition. The AT in $7 \mathrm{M}$ and $10 \mathrm{M}$ enables to obtain the HAp layer, which can be characterized as the most developed in terms of thickness and porosity. Finally, selected coated samples were investigated in terms of surface wettability test managed in time relation, which for the results confirm high hydrophilicity of the surfaces. Conducted research shows that the low-temperature hydrothermal processing could be considered for a possible adaptation in the drug encapsulation and delivery systems.
\end{abstract}

Keywords: ultrafine-grained structure; titanium beta alloys; mechanical alloying; low-temperature hydrothermal treatment; alkaline treatment; wettability tests

\section{Introduction}

Titanium and its alloys are the most commonly used metallic materials in the biomedical field. These biometals have found application in orthopedics, not only maxillofacial but also, dental implants under load-bearing conditions [1]. Their use is justified by low Young's modulus, low density, and high corrosion resistant properties [1,2].

Recently, researchers have demonstrated that titanium alloys with beta-type structure have become a more enhanced class of biometals [3]. Modern beta type alloys contain nontoxic elements and are characterized by high strength, very low elastic modulus, good corrosion resistance, and excellent biocompatibility in comparison to other biometals [4,5]. An examples of modern beta titanium alloys are Ti-5Mo-5Ag [6], Ti-xMo (x-23\%-35wt.\%) [5,7], Ti14Zr16Nb [4], Ti23Zr25Nb [4], Ti-6Al-2Nb-2Ta-1Mo [8], Ti-15Mo-Zr [9]. It is worth mentioning that a great effort was put into the research and development of Ti-Mo alloys because of their surgical application $[10,11]$.

Contemporary researchers have demonstrated that the properties of Ti-Mo alloys can be adjusted depending on the Mo content. As the Mo concentration increases, the hardness increases, and the 
Young modulus decreases [12]. This approach gives the possibility to adapt the properties to the specific application. The addition of approximately $10 \% \mathrm{Mo}$, or more, allows only to $\operatorname{Ti}(\beta)$ phase to appear in Ti-Mo alloy, however, a high cooling rate for lower stabilizing element addition [7] remains needed. Additionally, the properties of alloys do not depend only on chemical composition, but also on microstructure modification [3]. They can be enhanced by nano-structurization. To receive the nanoor ultrafine-grained structure, the mechanical alloying (MA) process can be applied. New prospects appear with nanostructure materials, which exhibit better mechanical and physicochemical properties in comparison to their microcrystalline counterparts. Recent studies have shown that nanostructuring of titanium can considerably improve not only the mechanical properties but also the biocompatibility [13].

In general, biometals possess lower biocompatibility and osseointegration characteristics in comparison to bioceramic materials. To improve the above, a bioceramic covering can be applied [14]. The most common approach in commercial practice uses the hydroxyapatite (HAp) covering $[15,16]$.

Hydroxyapatite is one of the largest groups of calcium phosphate-based materials. The chemical composition of HAp is $\left[\mathrm{Ca}_{10}\left(\mathrm{PO}_{4}\right)_{6}(\mathrm{OH})_{2}\right]$. HAp possesses chemical similarity to the mineral component of bones and hard tissues [15]. Moreover, HAp can be characterized by high biocompatibility, bioactivity, and resorbability. In terms of thermodynamics, it also provides the highest stability in body fluids among all calcium phosphate salts [17]. Due to its high bio properties, HAp has found a wide range of applications-it is used as materials for implants and prostheses; as a coating material to improve biocompatibility and osteointegration; as also drug delivery systems to control the release of drugs [18].

HAp coating can be produced by a plasma spraying [19], immersion in simulated body fluid [20], laser deposition [21], ion beam dynamic mixing [22], ion beam deposition [23], sol-gel precipitation [24], hydrothermal treatment [25,26], ion implantation, alkaline treatment [27], electrochemical methods [24], and others. Plasma spraying is the most common commercial method used to cover titanium implants [28]. However, this technique may not provide an equal thickness especially in the complex geometries, sufficient adhesion to the substrate, and characterize the HAp-cover by inhomogeneous phase composition and low crystallinity [29].

The alternative approach, without the disadvantages like plasma spraying, is for example the hydrothermal treatment [28]. This method enables the creation of a high-quality HAp-cover with $\mathrm{Ca} / \mathrm{P}$ ratio similar to the stoichiometric value of HAp. Furthermore, it is possible to control the thickness of the layer or morphology, size, and orientation of HAp-grains [25].

To embed HAp cover on the titanium substrate, there is a need for specific surface activation. The most frequently applied methods are alkali treatment [28], acidic treatment [25], and micro-arc oxidation (MAO) [30]. In this work, the alkali treatment approach is carried out, focusing the conducted research on its simplicity understand as easy to control, repeatable, efficient and, also, easy to scaleup process. The most common in use solution for the alkali treatment is $5 \mathrm{M} \mathrm{NaOH}[27,28,31]$. The purpose of the alkaline treatment is to create the oxide-hydroxide layer on the titanium surface with the specific topography and positive surface charge [32]. As a result of the alkaline treatment, the surface bioactivity is enhanced. It enables the further formation and strong bonding of the HAp coating towards the original surface $[33,34]$. Such a process can be observed under the condition of a positively charged layer attracting the negatively charged phosphates ions, which allows the absorption of calcium ions on the treated surface [32].

Hydrothermal treatment is based on the chemical dissolution of HAp crystals from an aqueous solution with calcium and phosphate precursors. This process is carried out in an autoclave or pressure vessel at elevated temperature and pressure [32]. During the hydrothermal treatment, the $\mathrm{pH}$ and temperature control of the solution is crucial [35]. The HAp crystals morphology and, also, adhesion between the embedded surface and HAp coating strongly depends on $\mathrm{pH}$ and temperature factors [36-38]. Moreover, the temperature is related to the phase purity and $\mathrm{Ca} / \mathrm{P}$ ratio. To begin the chemical deposition the boiling point of the solution has to be achieved, although the higher temperature the results are better. Regarding the relation between $\mathrm{pH}$ and HAp crystals morphology, the high $\mathrm{pH}$ value facilitates the growth of a spherical or short rod-like form of HAp [16]. However, 
rod- or plate-like structures appear under acidic or neutral conditions. Furthermore, hydrothermal treatment can differ in the chemical composition of the solution. Calcium chelating agents and various organic surfactants are the most common HAp sources for hydrothermal treatment. Although, EDTA, as the most used calcium chelating agent, found the application in HAp production. Ca-EDTA is simple to decompose under hydrothermal conditions. This modifier enables the formation of longer HAp crystals at a lower temperature.

The present study investigates the formation of the hydroxyapatite layers on the TixMo $(x=23,27$, $35 \mathrm{wt.} \%$ ) ultrafine-grained alloys obtained by mechanical alloying and hot pressing approach. The HAp covers were obtained after the proposed low-temperature procedures. Surface treatments rely on acidic etching, alkaline, and finally hydrothermal treatment. All process stadiums were investigated structurally and was depictured on the schematic process illustration in Figure 1.

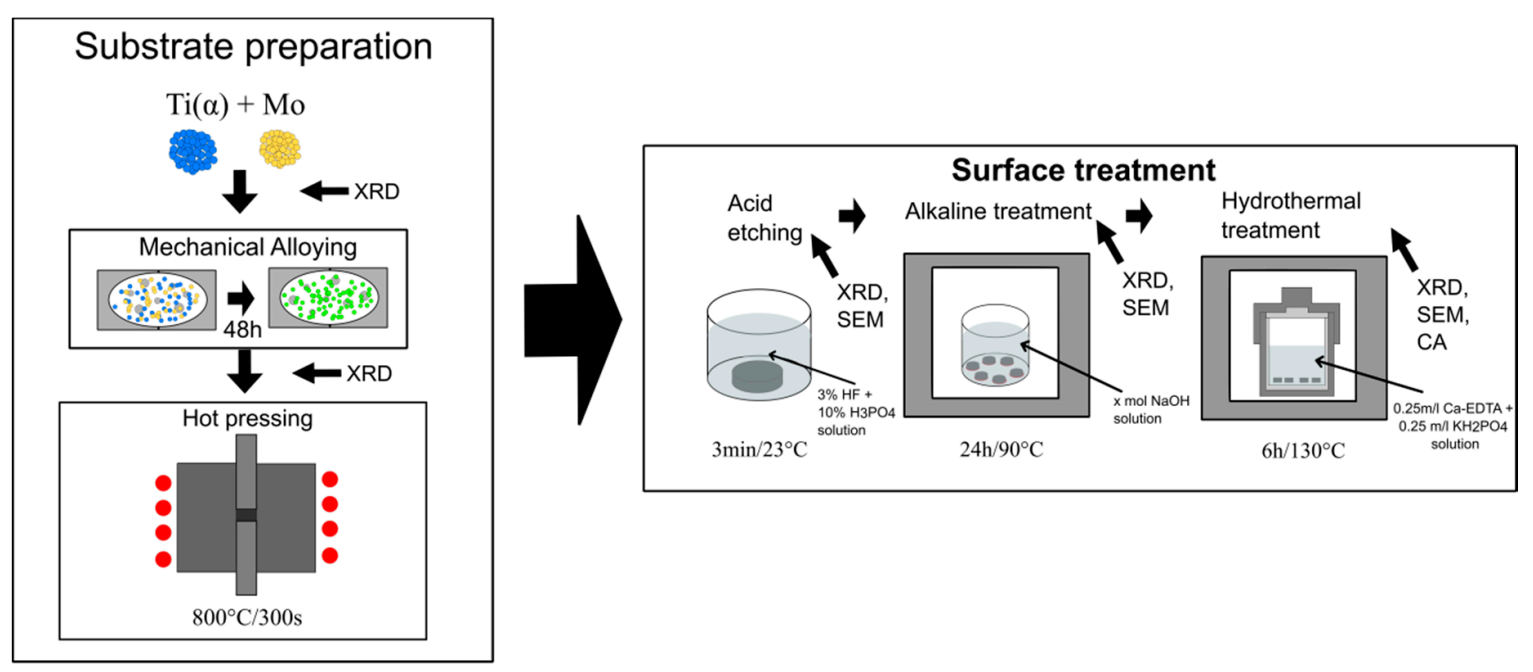

Figure 1. Schematic process illustration.

A low-temperature surface treatment processing applied for sintered ultrafine-grained TixMo alloys remain attractive for further recognition in drug encapsulation and delivery systems. Processing temperatures and applied for treatment solutions for the above stay relevant factors.

The starting sample compositions and in the same resulting phase relation with its inherent structure and size, influence as the research shows a step-by-step processing relation. The phase grain boundaries and the primary powder particle grains that could be noticed for the sinters obtained in a specific way (revealed after etching), by its energetically favorable state influence further processing stadiums that mimic the substrate structure. Analyzed in this work, various molar concentrations of $\mathrm{NaOH}(5 \mathrm{M}, 7 \mathrm{M}, 10 \mathrm{M}, 12 \mathrm{M})$ alkaline solutions shows its influence on the treatment products, necessary however for further proper HAp layer formation and growth. The above points out also the dependence between the substrate activity characteristics and the applied solution concentration. Analyzed additional wettability characteristics of the obtained HAp layers correlate with not modified surfaces and base microcrystalline titanium, confirming its meaning and usability in a broad medical applications range.

\section{Materials and Methods}

\subsection{Materials and Specimens}

For the hydrothermal treatment surface functionalization, an ultrafine-grain base Ti23Mo, Ti27Mo, and Ti35Mo (wt.\%) alloy samples were fabricated by mechanical alloying (MA) and powder metallurgy (PM) methods, which for the details of preparation could be found in our earlier work [5,7]. The sintering procedure proposed in this work was the same for all samples and relay on the hot pressing in $800{ }^{\circ} \mathrm{C}$ 
in vacuum conditions which was schematically shown in Figure 2 . To prepare the $(\beta)$ titanium alloys, the commercial Ti (Alfa Aesar, 99.9\% purity, CAS:7440-32-6, Karlsruhe, Germany) and Mo (44 $\mu \mathrm{m}$, 99.6\%, CAS:7430-08-7 Sigma Aldrich, Karlsruhe, Germany) powders were used. The dimensions of the hot-pressed cylinder shape bulk samples were $5 \mathrm{~mm}$ high and $8 \mathrm{~mm}$ in diameter. In the next step, samples were mechanically abraded with 180 to 2500 -grit silicon carbide (SiC) grinding papers followed by polishing with $0.5 \mu \mathrm{m}$ diamond paste and cleaning in ethanol. Prepared samples were chemically etched in an acid solution of $3 \% \mathrm{HF}+10 \% \mathrm{H}_{3} \mathrm{PO}_{4}$ (Poch S.A., Gliwice, Poland) for $3 \mathrm{~min}$ and afterward washed in distilled water.

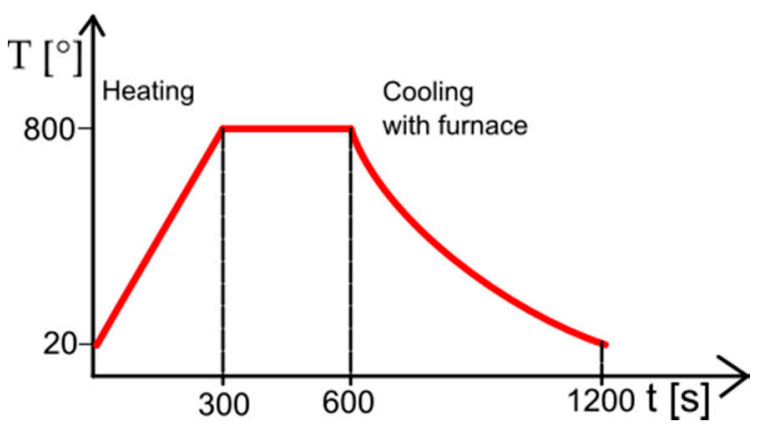

Figure 2. Schematic representation of the hot pressing process.

\subsection{Alkaline Treatment}

Alkaline treatment (AT) of TixMo $(x=23,27,35)$ alloys were performed in four different molar concentrations of $\mathrm{NaOH}$ (Poch S.A., Gliwice, Poland). Each alloy set of Ti23Mo, Ti27Mo, and Ti35Mo samples was treated in $5 \mathrm{M}, 7 \mathrm{M}, 10 \mathrm{M}$, and $12 \mathrm{M} \mathrm{NaOH}$ solution. The samples were anchored to the bottom of the glass beakers and filled with the $250 \mathrm{~mL}$ of $\mathrm{NaOH}$ solution. Subsequently, the beakers were put into the furnace and treated for $24 \mathrm{~h}$ at $90{ }^{\circ} \mathrm{C}$ conditions. At the end of the alkaline treatments, samples were washed in distilled water. After AT, the samples were marked as Table 1 shows.

Table 1. Sample indication after alkaline treatment.

\begin{tabular}{ccccc}
\hline Sample/Molar Concentration of $\mathbf{N a O H}$ & $\mathbf{5} \mathbf{M}$ & $\mathbf{7} \mathbf{M}$ & $\mathbf{1 0} \mathbf{M}$ & $\mathbf{1 2} \mathbf{M}$ \\
\hline Ti23Mo & 23-5AT & 23-7AT & 23-10AT & 23-12AT \\
Ti27Mo & 27-5AT & 27-7AT & 27-10AT & 27-12AT \\
Ti35Mo & 35-5AT & 35-7AT & 35-10AT & 35-12AT \\
\hline
\end{tabular}

\subsection{Hydrothermal Treatment}

Hydroxyapatite coatings were synthesized from CA-EDTA solution under hydrothermal conditions. The preparation of the solution was divided into two stages. Firstly, Ca-EDTA (Sigma-Aldrich, CAS: 62-33-9, Saint Louis, MO, USA) and $\mathrm{KH}_{2} \mathrm{PO}_{4}$ (Sigma-Aldrich, CAS: 7778-77-0, Saint Louis, MO, USA) were dissolved in deionized water with $0.25 \mathrm{~mol} / \mathrm{L}$ and $0.15 \mathrm{~mol} / \mathrm{L}$, respectively, to prepare $200 \mathrm{~mL}$ of solution. Secondly, the $\mathrm{pH}$ of the solution was titrated by $1 \mathrm{~mol} / \mathrm{L} \mathrm{NaOH}$ to the value of 8.9. The fresh resulting mixture was transferred into glass beakers with placed earlier prepared AT samples, that were next sealed and put into the furnace. The hydrothermal treatment of the samples was conducted at $130^{\circ} \mathrm{C}$ for $6 \mathrm{~h}$ (time was measured from the time when the boiling point was reached) with the next cooling to room temperature with the furnace. The sample was removed from the beakers and dried at room temperature. After hydrothermal treatment (HT), the samples were marked as presented in Table 2. 
Table 2. Sample indication after hydrothermal treatment.

\begin{tabular}{ccccc}
\hline Sample/Molar Concentration of $\mathbf{N a O H}$ & $\mathbf{5} \mathbf{M}$ & $\mathbf{7} \mathbf{M}$ & $\mathbf{1 0} \mathbf{M}$ & $\mathbf{1 2} \mathbf{M}$ \\
\hline Ti23Mo & $23-5 \mathrm{HT}$ & $23-7 \mathrm{HT}$ & $23-10 \mathrm{HT}$ & $23-12 \mathrm{HT}$ \\
Ti27Mo & $27-5 \mathrm{HT}$ & $27-7 \mathrm{HT}$ & $27-10 \mathrm{HT}$ & $27-12 \mathrm{HT}$ \\
Ti35Mo & $35-5 \mathrm{HT}$ & $35-7 \mathrm{HT}$ & $35-10 \mathrm{HT}$ & $35-12 \mathrm{HT}$ \\
\hline
\end{tabular}

\subsection{Materials Characterization}

At every stage of sample preparation, an X-ray diffraction (XRD) (Empyrean, Panalytical, Almelo, Netherlands) analysis was conducted by the Panalytical Empyrean equipment with the copper anode $(\mathrm{CuK} \alpha-1.54 \AA$ ) at a Brag-Brentano reflection mode configuration with $45 \mathrm{kV}$ and $40 \mathrm{~mA}$ parameters. The measurement parameters were set up for $20^{\circ}-90^{\circ}$ with a $15 \mathrm{~s}$ per step $0.0167^{\circ}$ in all cases.

The following structural models were used:

(1) Base specimens:

- $\quad \operatorname{Ti}(\alpha)$-ref. code 04-003-5042

- $\quad \mathrm{Ti}(\beta)-\mathrm{Ti}_{0.9} \mathrm{Mo}_{0.1}$-ref. code 04-018-6034

(2) Alkali treatment:

- $\quad \mathrm{TiO}-$ ref. code 01-086-2352

- $\quad \mathrm{Na}_{2} \mathrm{Ti}_{2} \mathrm{O}_{4}(\mathrm{OH})_{2}$-ref. code $00-057-0123$

- $\mathrm{Na}_{0.55} \mathrm{Mo}_{2} \mathrm{O}_{4}$-ref. code 00-040-1022

(3) Hydrothermal treatment:

- $\quad \mathrm{Ca}_{10}\left(\mathrm{PO}_{4}\right)_{6}(\mathrm{OH})_{2}$-ref. code 01-080-3958

- $\mathrm{Na}_{2} \mathrm{HPO}_{4}$-ref. code 00-001-0997

For detailed structure analysis, a collation of the pairs of the highest intensity peak relations of processing product with the substrate was revealed. The data refers to obtained patterns of the processing products depicted in a graph relation, which for a proportion of the highest intensity peak of the substrate were related to the highest intensity peak of the product phases. Indirectly presented data represent a quantitative collation, which for diminished base substrate intensity with increasing intensity of products corresponds to a layer thickness growth. Additionally, the growing intensity of the product phases corresponds to its higher crystallinity and volumetric amount related to the collected instrument data. Further conclusions could also be drawn from the presented data.

Scanning electron microscopy in the SE-mode (SEM, MIRA3 Tescan) was used to characterize the surface after all stages of modification.

The contact angles (CA) of analyzed surfaces were determined by the sessile drop method. The measurements were performed by a Drop Shape Analyzer-DSA25 instrumentation (KRÜSS GmbH, Hamburg, Germany) and the KRÜSS ADVANCE 1.5.1.0 software instrumentation (KRÜSS GmbH, Hamburg, Germany). The used parameters were as follows:

- measuring liquid: glycerol,

- drop volume: $0.5 \mu \mathrm{L}$,

- dosing speed $0.2 \mathrm{~mL} / \mathrm{min}$,

- measuring time: $8 \mathrm{~s}$,

- probing frequency for multiple measurements: $50 \mathrm{fps}$,

- base cut off: automatic/manual,

- CA fitting method: Young Laplace,

- measurements conditions: ambient $23^{\circ} \mathrm{C}$. 


\section{Results and Discussion}

In the present study, the hydroxyapatite cover on the ultrafine-grained beta titanium alloys was obtained and afterward evaluated focusing on its formation criteria. Using the various molar concentrations of $\mathrm{NaOH}(5 \mathrm{M}, 7 \mathrm{M}, 10 \mathrm{M}, 12 \mathrm{M})$ the influence of the alkali treatment on HAp layer growth were investigated, while the rest of the parameters were constant. Furthermore, the chemical composition impact of beta titanium ultrafine-grained alloys on the surface modification approach was also investigated.

\subsection{Base Materials—Ti-Mo Systems}

Figure 3 shows the XRD patterns of Ti-xMo bulk sample ultrafine-grained alloys. In all of the analyzed cases, the main phase corresponds to $\mathrm{Ti}(\beta)$ type structure- $-\mathrm{Ti}_{0.9} \mathrm{Mo}_{0.1}$. However, for all systems, a small amount of the $\operatorname{Ti}(\alpha)$ phase could be noticed. The amount of $\operatorname{Ti}(\alpha)$ phase remains strictly connected with the beta stabilizing Mo content in the starting powder mixtures. Additionally, an increase in molybdenum content causes also a decrease in the beta phase unit cell, which is revealed by a peak shift to larger angles. The reductions in the interplanar distance $\left(\Delta \mathrm{d}_{\mathrm{hkl}}\right)$ between references phase and MA alloys set as follows $0.002513,0.004263$, and 0.014648 by increasing molybdenum content in the alloy (Figure 3). The above relation could be only explained by the bcc unit cell transition from titanium-based one to molybdenum which for the cell dimension is lower. In the specific compared relation of $\mathrm{Ti}_{0.9} \mathrm{Mo}_{0.1}$ to Mo lattice parameters dimension present as fallowed 325.7 to $314.7 \mathrm{pm}$. A similar effect was already observed in our earlier research [5] which details structural estimation confirming such behavior; however, other intermediate beta phases with growing molybdenum content were confirmed like MoTi.

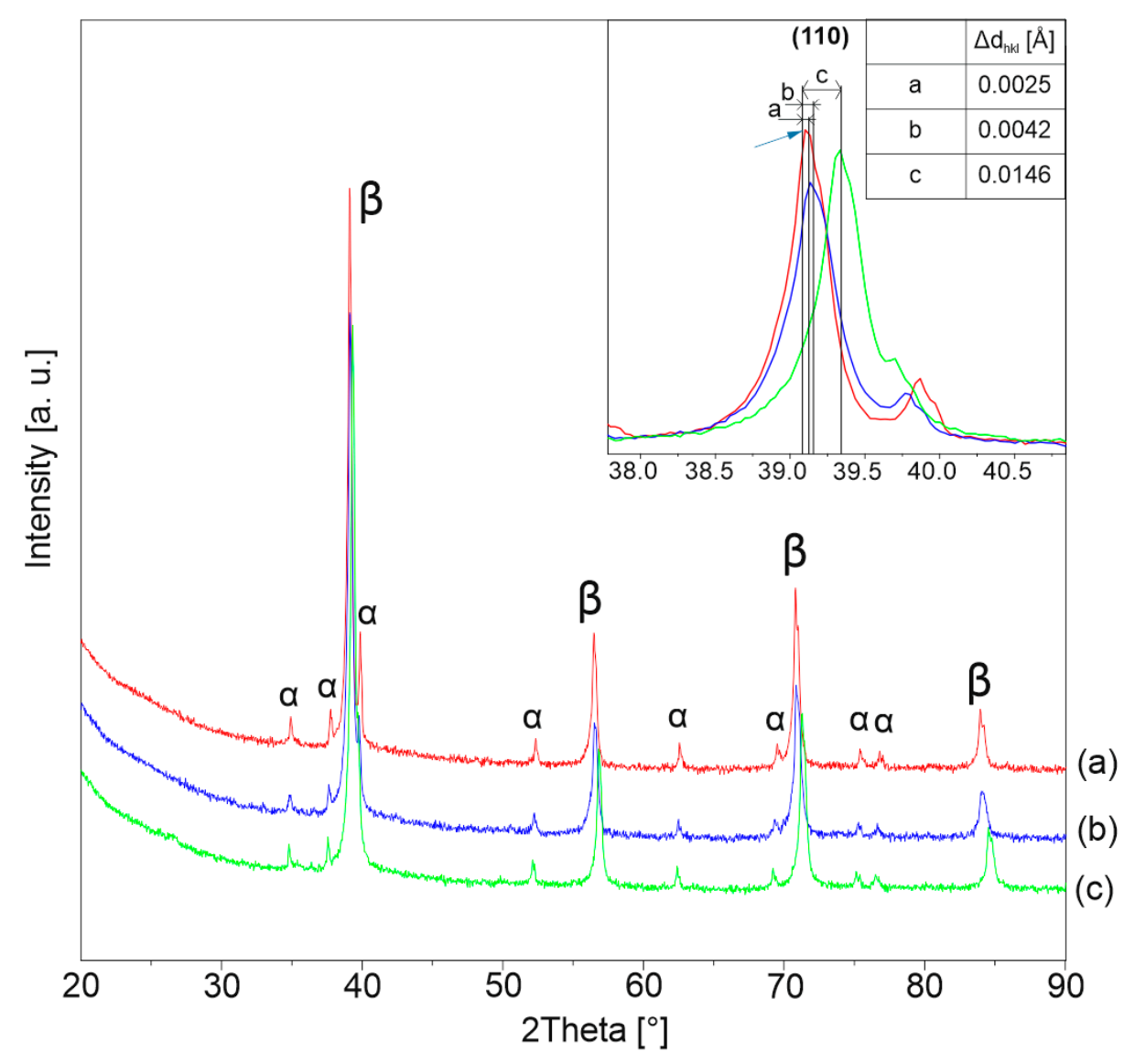

Figure 3. XRD patterns of sintered specimens: (a) Ti23Mo, (b) Ti27Mo, (c) Ti35Mo. 
A hot pressing of the prepared by MA blends allows obtaining alloys with an ultra-fine grain structure for all proposed compositions, as shown in Figure 4. The average grain size of Ti23Mo oscillates $1.097 \pm 0.216$ (Figure 4 ). The microstructure remains homogenous and shows a polygonal grain morphology suggesting fine kinetics between the components and stable state of the obtained systems.

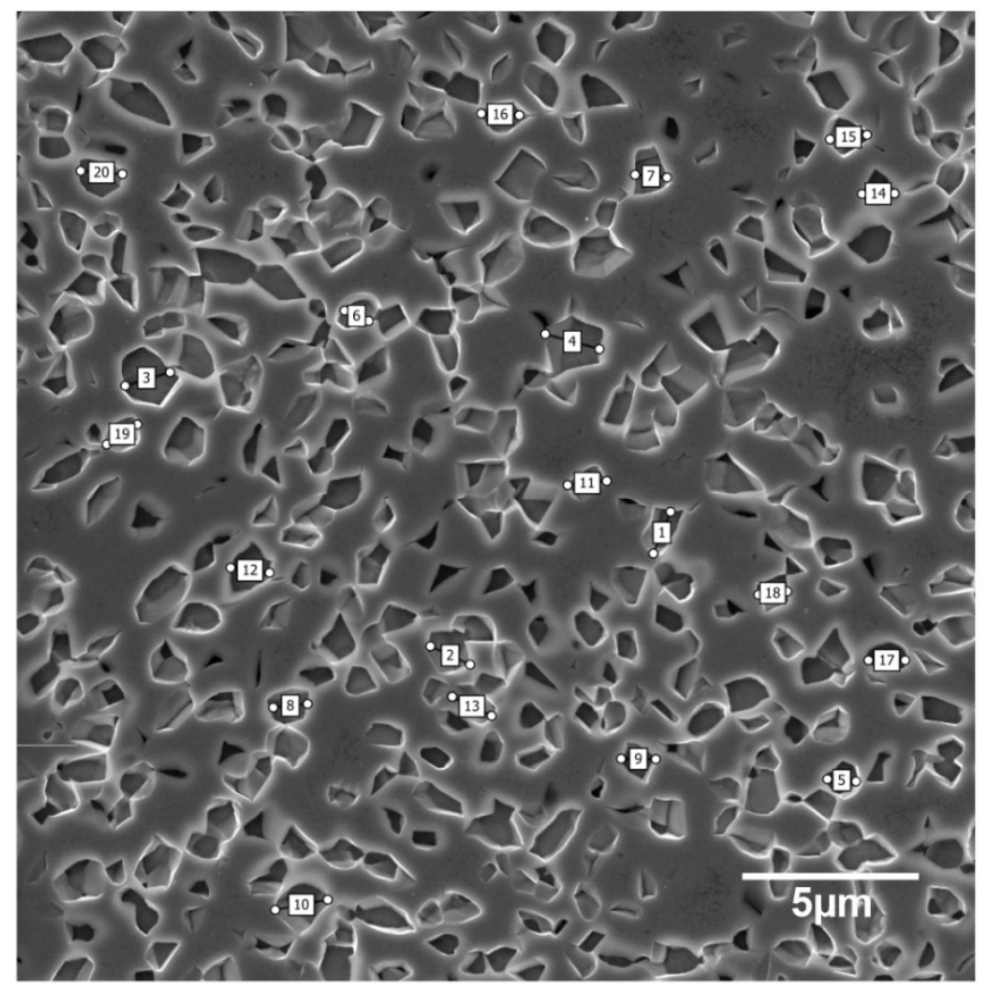

\begin{tabular}{l|l} 
Number & Grain size $[\mu \mathrm{m}]$ \\
\hline 1 & 1.273 \\
\hline 2 & 1.237 \\
\hline 3 & 1.324 \\
\hline 4 & 1.587 \\
\hline 5 & 0.812 \\
\hline 6 & 0.745 \\
\hline 7 & 0.905 \\
\hline 8 & 0.977 \\
\hline 9 & 0.980 \\
\hline 10 & 1.512 \\
\hline 11 & 1.112 \\
\hline 12 & 1.111 \\
\hline 13 & 1.239 \\
\hline 14 & 0.921 \\
\hline 15 & 1.054 \\
\hline 16 & 1.078 \\
\hline 17 & 1.036 \\
\hline 18 & 1.034 \\
\hline 19 & 0.821 \\
\hline 20 & 1.183 \\
\hline Mean & $1.097 \pm 0.216$ \\
\hline
\end{tabular}

Figure 4. SEM microphotographs of Ti23Mo and the determination of average grain size.

\subsection{Acid Etching}

The chemical etching step was applied in the proposed procedure to develop a surface roughness. Figure 5 shows the SEM microphotographs of Ti23Mo, Ti27Mo, and Ti35Mo surface after etching in 3\% $\mathrm{HF}+10 \% \mathrm{H}_{3} \mathrm{PO}_{4}$ acid solution. The etching process runs firstly along the primary powder particle grains, some of the effects could be also observed for the phase grain boundaries. In the case of acid etching of Ti27Mo, the obtained effect remains inhomogeneous. Etching takes place on the entire surface along the powder particle grains, but the grain boundaries etching can be indicated in some areas. Ti35Mo alloy is the most resistant to acidic etching in the proposed process solution. The primary powder particles cannot be pointed out. The etching process runs along the grain boundaries, but the final effect remains fine.

\subsection{Alkali Treatment in $\mathrm{NaOH}$ Solution with Different Molar Concentration}

Figures 6-8 shows the XRD patterns of the alkali-treated surface of the TixMo alloys. The diffraction patterns point out mostly $\operatorname{Ti}(\beta)$ and $\operatorname{Ti}(\alpha)$ phases derived from the substrate. However, the titanium oxide and phases base on sodium $\left(\mathrm{Na}_{2} \mathrm{Ti}_{2}(\mathrm{OH})_{4}\right.$ and $\left.\mathrm{Na}_{0.55} \mathrm{Mo}_{2} \mathrm{O}_{4}\right)$ can be indicated. The peaks from the layer phases are characterized by low intensity. This indicates a slight thickness of the created layers. Ti35Mo sample possesses the highest resistance to alkaline treatment. XRD patterns of Ti35Mo do not reveal $\mathrm{Na}_{2} \mathrm{Ti}_{2}(\mathrm{OH})_{4}$ phase regardless of the $\mathrm{NaOH}$ concentration. The largest quantitative share of the $\mathrm{Na}_{2} \mathrm{Ti}_{2}(\mathrm{OH})_{4}$ phase can be observed for the samples 23-7AT and 27-7AT. 


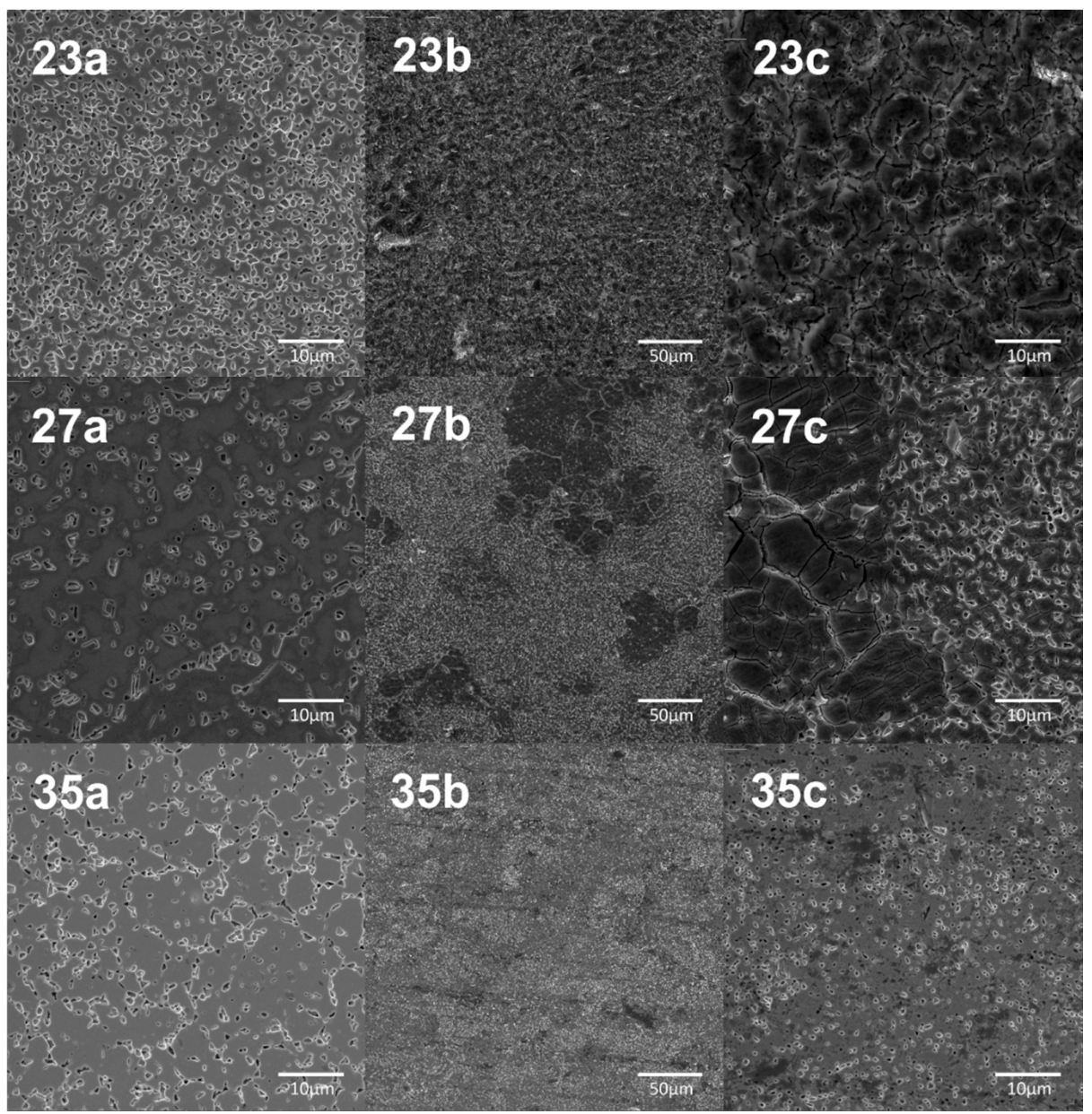

Figure 5. SEM microphotographs of Ti23Mo, Ti27Mo, Ti35Mo base materials-23a, 27a, 35a, respectively, and after acid etching at the different magnification $(23 b, 23 c, 27 b, 27 c, 35 b, 35 c)$.

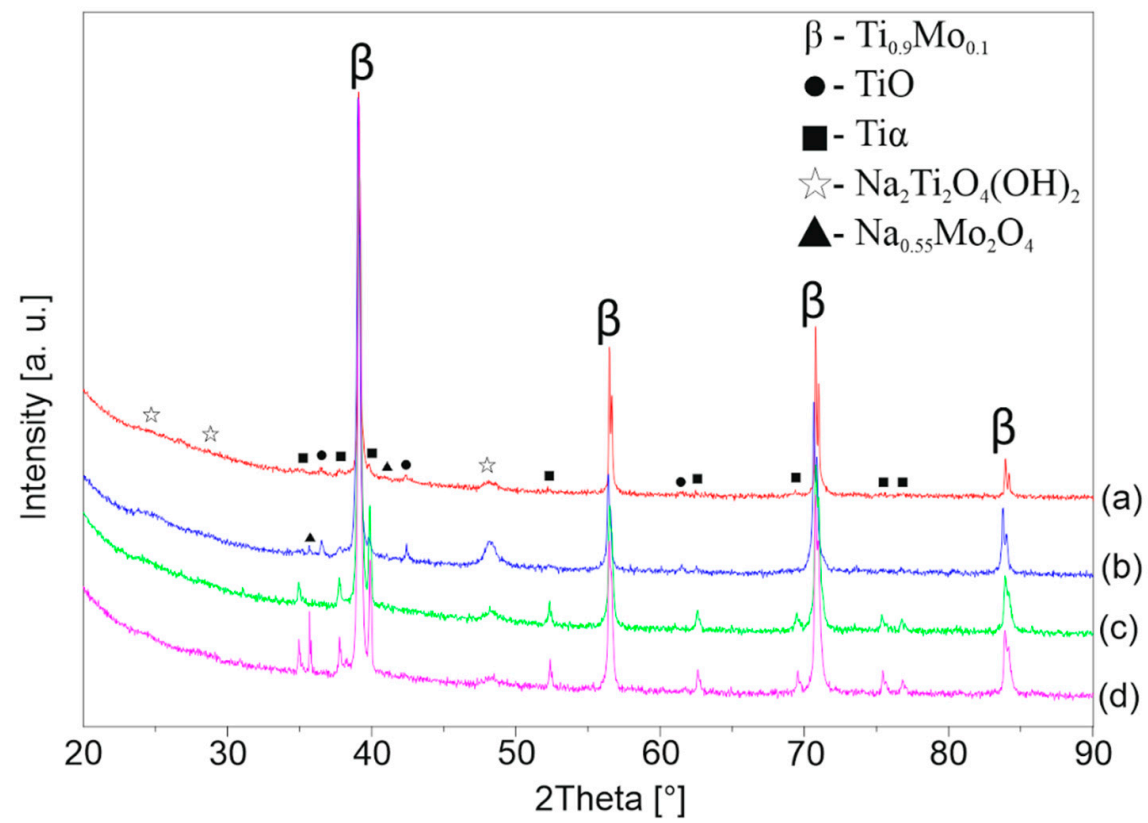

Figure 6. XRD patterns of Ti23Mo after alkaline treatment in (a) $5 \mathrm{M}$, (b) $7 \mathrm{M}$, (c) $10 \mathrm{M}$, (d) $12 \mathrm{M}$ $\mathrm{NaOH}$ solutions. 


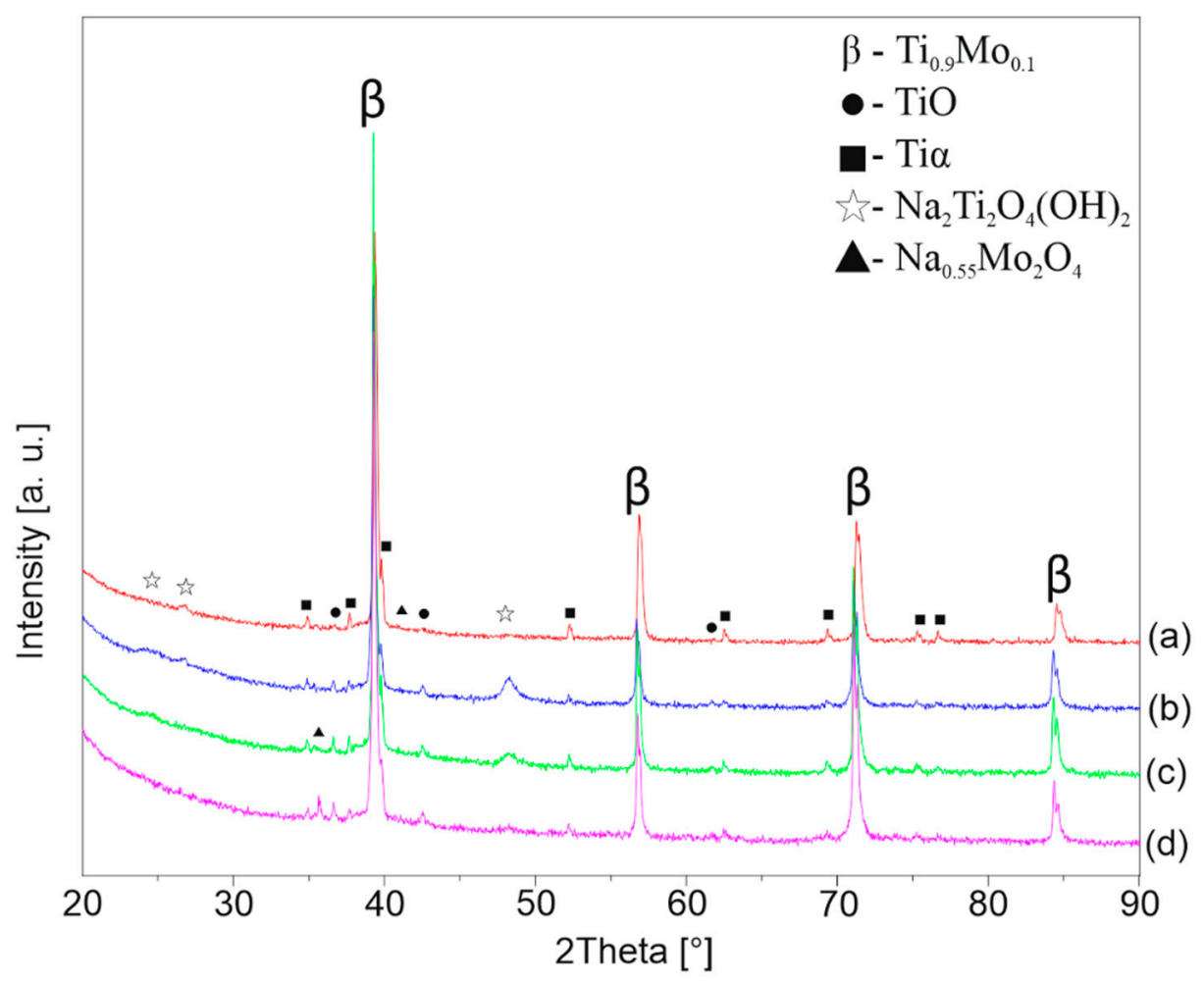

Figure 7. XRD patterns of Ti27Mo after alkaline treatment in (a) $5 \mathrm{M}$, (b) $7 \mathrm{M}$, (c) $10 \mathrm{M}$, (d) $12 \mathrm{M}$ $\mathrm{NaOH}$ solutions.

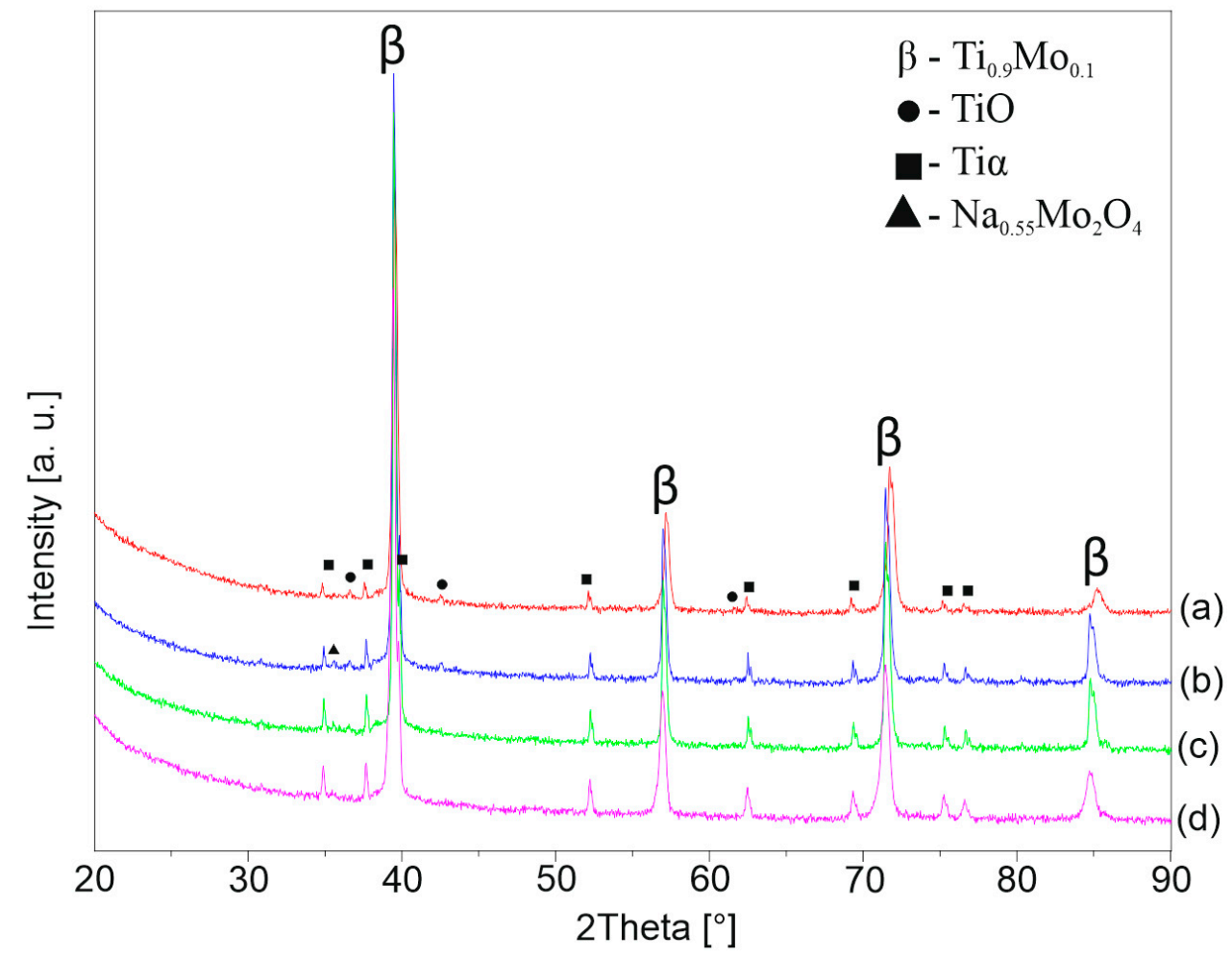

Figure 8. XRD patterns of Ti35Mo after alkaline treatment in (a) $5 \mathrm{M}$, (b) $7 \mathrm{M}$, (c) $10 \mathrm{M}$, (d) $12 \mathrm{M}$ $\mathrm{NaOH}$ solutions. 
The surface morphology analysis after alkaline treatment with the various $\mathrm{NaOH}$ solution for $24 \mathrm{~h}$ at $90^{\circ} \mathrm{C}$, was shown in Figure 9. The results indicated that the surface morphology depends on the molar concentration of $\mathrm{NaOH}$ solution and, also, the chemical composition of the base materials. In all cases, the created layers are characterized by surface cracking. Formed structure imitates the primary powder and phase grains because of the privileged higher energy regions with easier kinetics. For the abovementioned, it is worth noticing that the reaction kinetics indirectly depend on a substrate relation and solution concentration, which may lead to an unexpected product phase stability diminishment, which, in our case, is visible in an intense layer cracking and delamination from the substrate. The depth of cracks and the size of formed structures have the smallest value in the case of Ti35Mo alloy.

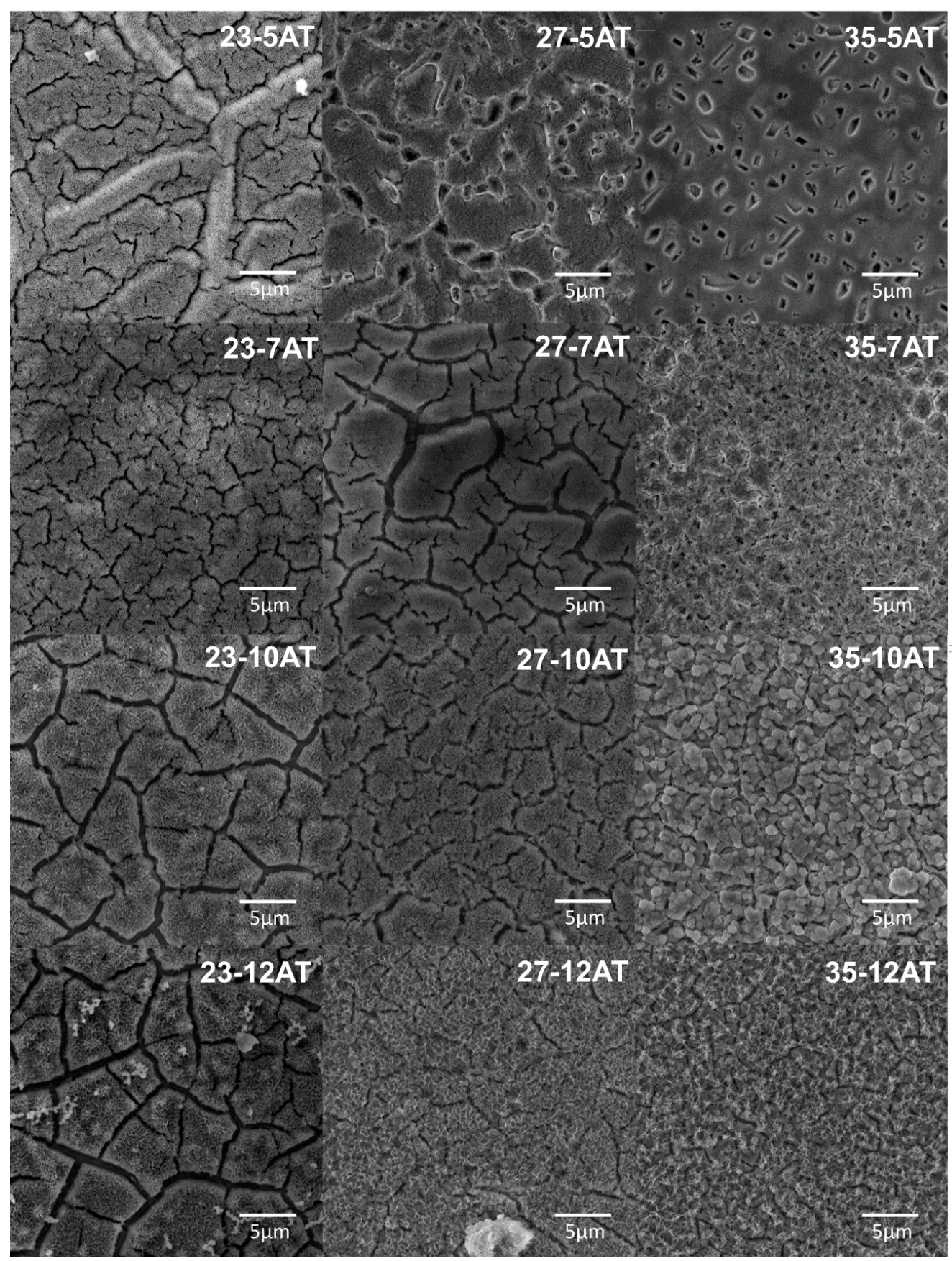

Figure 9. SEM microphotographs of Ti23Mo, Ti27Mo, Ti35Mo, after acid etching and alkaline treatment in various molar concentrations of $\mathrm{NaOH}$. 
Additionally, $\mathrm{NaOH}$-soaked samples (at all concentrations) exhibit a porous cellular-looking morphology. Only the sample Ti35Mo $10 \mathrm{M}$ possesses a unique microstructure morphology, which can be determined as an island-like morphology.

\subsection{Hydrothermal Treatment in Ca-EDTA Solution}

The XRD patterns of hydrothermally treated TixMo alloys confirm the presence of HAp on the sample surfaces, as shown in Figures 10-12. The XRD patterns obtained for the samples after AT in $7 \mathrm{M}, 10 \mathrm{M}$, and HT are characterized by sharp and high-intensity HAp peaks. Additionally, no peaks correspond to any other crystalline calcium phosphate phases. Disodium phosphate $\left(\mathrm{Na}_{2} \mathrm{HPO}_{4}\right)$ impurities could be indicated in the layer, which derives from the Ca-EDTA solution. This phase forms a binder between the hydroxyapatite crystals. The patterns obtained for the samples after AT in $12 \mathrm{M}$ and HT are characterized by a low intensity of the peaks originating from the HAp phase.

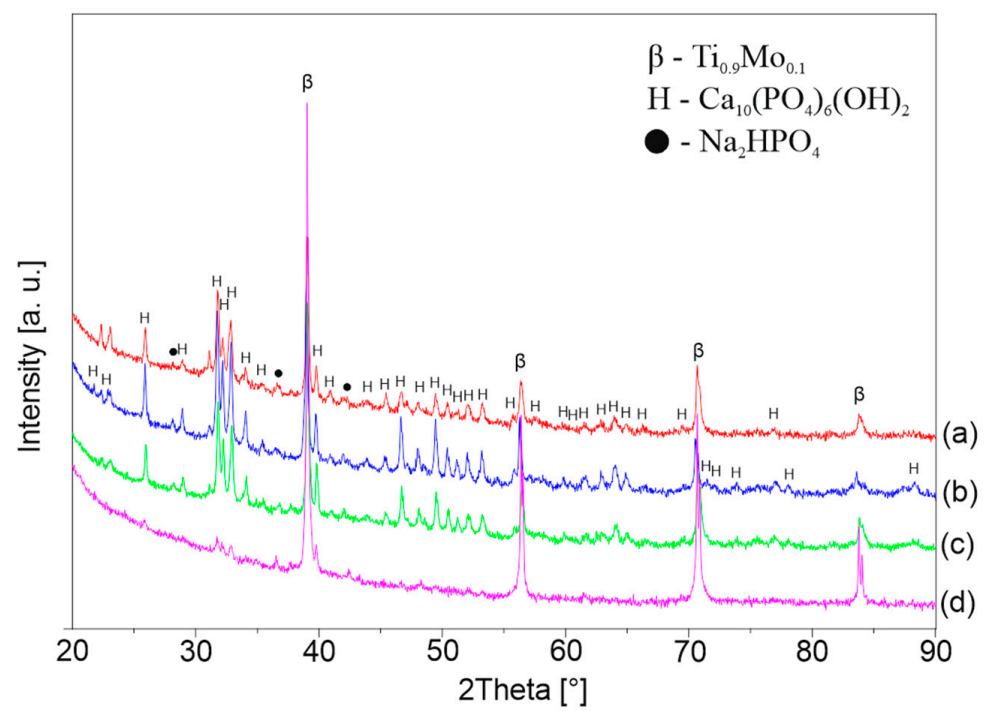

Figure 10. XRD patterns of (a) 23-5HT, (b) 23-7HT, (c) 23-10HT, (d) 23-12HT.

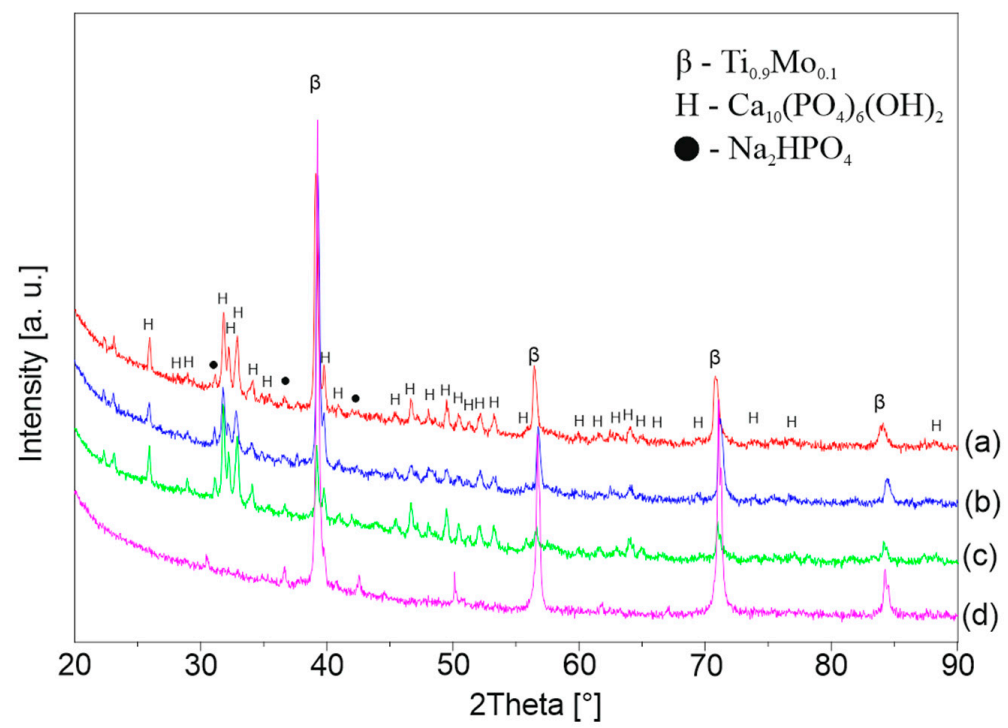

Figure 11. XRD patterns of (a) 27-5HT, (b) 27-7HT, (c) 27-10HT, (d) 27-12HT. 


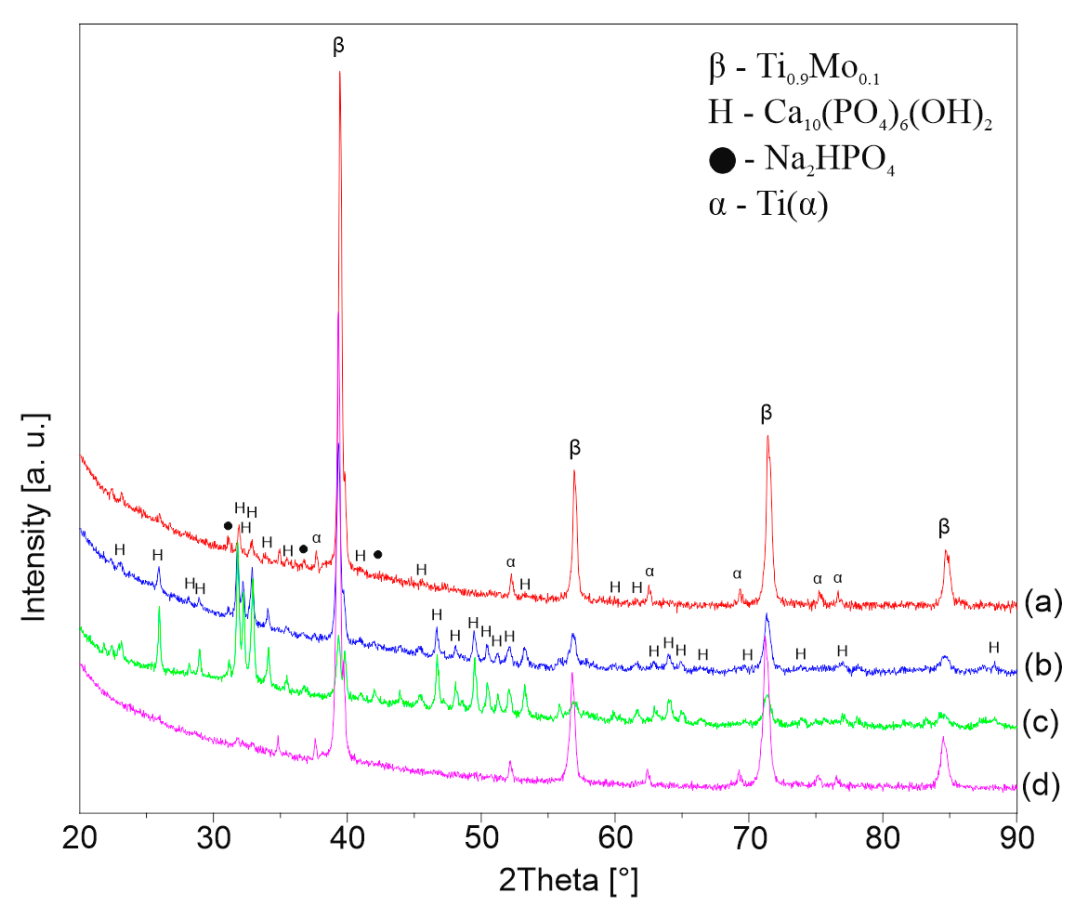

Figure 12. XRD patterns of (a) 35-5HT, (b) 35-7HT, (c) 35-10HT, (d) 35-12HT.

The overall morphology of the obtained after HT process surfaces, indicates the existence of many uniform cavernous-like HAp microstructure with needle-like HAp particles, as is presented in Figure 13. However, preceding alkaline treatment has a significant influence on HAp formation. SEM microphotographs of 23-7HT and 35-7HT show HAp covers on Ti $(\beta)$ alloys, which are characterized by high surface development and open porosity. HAp layers formed on samples after $10 \mathrm{M}$ AT are consistent and possess pores with a larger dimension than samples after $7 \mathrm{M}$ AT. It is relevant for the biomedical application when surfaces that contact directly with a tissue possess the possibilities to be colonized and overgrow by bone tissue. As the molar concentration of $\mathrm{NaOH}$ increased from $10 \mathrm{M}$ to $12 \mathrm{M}$, the HAp phase does not cover the entire surface and exhibits an island-like morphology. The abovementioned conclusion indicates low stability of the AT products in the case of $12 \mathrm{M} \mathrm{NaOH}$ solution, which does not provide a proper anchor for the HT product phase.

Structural collated data in the graph (Figure 14), represents the ratio of the intensity between the peak of the post-products phases and the $\operatorname{Ti}(\beta)$ phase, which shows the differences in the reaction after AT and the next HT. It is worth noticing that the peak ratio relates to the highest intensity peaks for each phase that corresponds to the following family of the plane: (111) for TiO-cubic, (020) for $\mathrm{Na}_{2} \mathrm{Ti}_{2} \mathrm{O}_{4}(\mathrm{OH})_{2}$-orthorhombic, (-102) for $\mathrm{Na}_{0.55} \mathrm{Mo}_{2} \mathrm{O}_{4}$-monoclinic, (121) for HAp-hexagonal, and also (110) for $\operatorname{Ti}(\beta)$ phase. The abovementioned data confirm the earlier conclusion about the processing products, that mimic the substrate, which was also confronted with the SEM analysis discussion.

Regarding the AT product ratio presents a complex overview. Although, it does not reveal the relation between solution concentration or substrate composition and surface response. Locally, for the same substrate composition, some tendency could be observed. For Ti23Mo example, the $\mathrm{TiO}$ and $\mathrm{Na}_{2} \mathrm{Ti}_{2} \mathrm{O}_{4}(\mathrm{OH})_{2}$ product phase amount grows when the solution concentration increases from $5 \mathrm{M}$ to $7 \mathrm{M}$. However, further $10 \mathrm{M}$ and $12 \mathrm{M}$ treatment exposes a decrease or even absence in the case of TiO product phase. A familiar relation could be observed in the case of the Ti27Mo sample, although only for the $\mathrm{Na}_{2} \mathrm{Ti}_{2} \mathrm{O}_{4}(\mathrm{OH})_{2}$ product phase. 


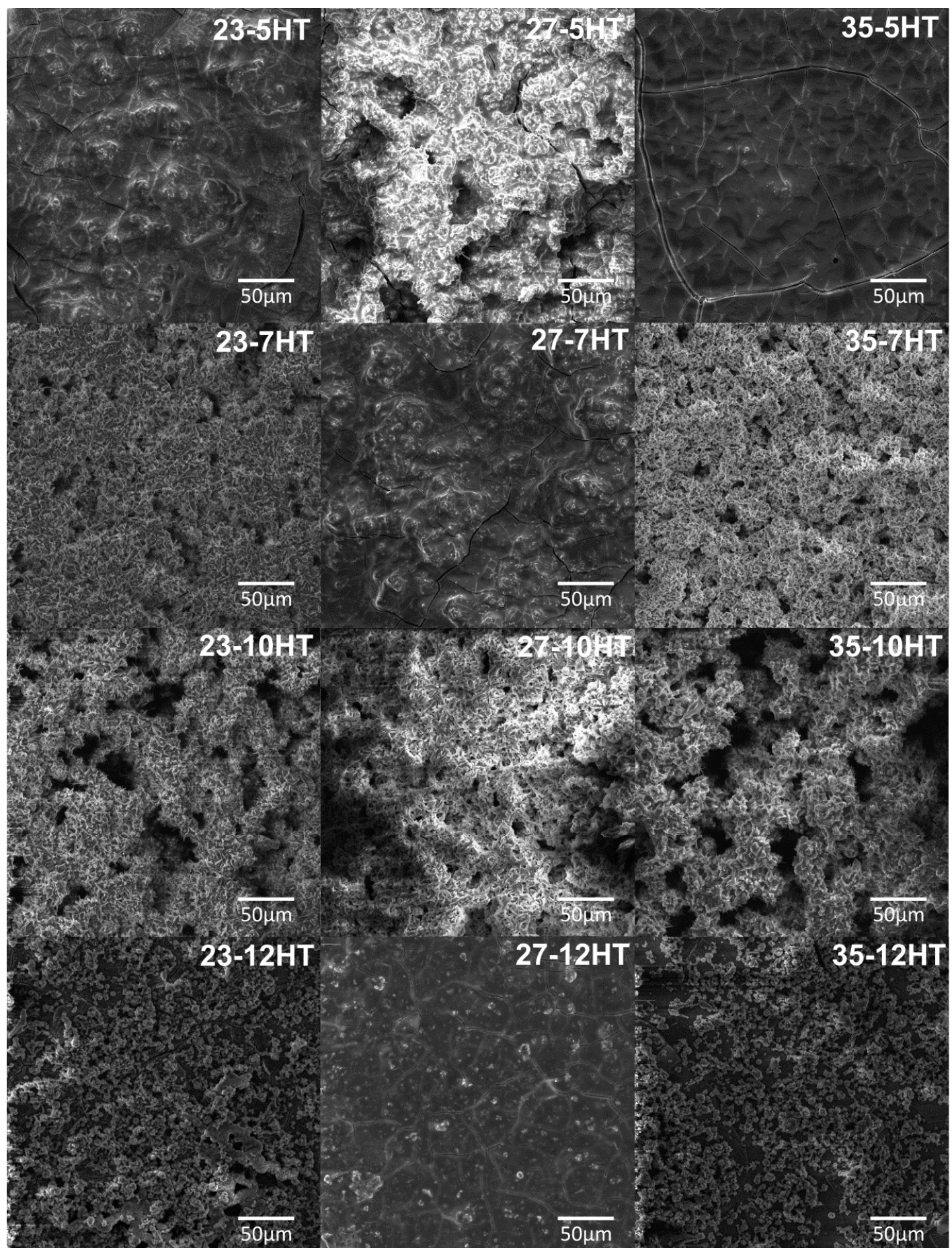

Figure 13. SEM microphotographs of Ti23Mo, Ti27Mo, Ti35Mo, after acid etching, alkaline treatment in various molar concentrations of $\mathrm{NaOH}$, and hydrothermal treatment.

The represented data confirms the HAp structural response after the HT in all analyzed experimental examples. However, in some cases, in a very low degree. In the case of the HT products, it stays important that the related value of $\mathrm{I}_{\mathrm{HAp}(121)} / \mathrm{I}_{\beta(110)}$ ratio depends indirectly on earlier AT treatment. Although, AT products were not noticed in the patterns after HT even when an HAp intensity was very low. The reason for this behavior is probably connected with the low stability of products after AT. The obtained results were assessed in terms of structural relations, understood as the highest HAp intensity ratio. This criterion indicates the samples after $10 \mathrm{M}$ AT. 


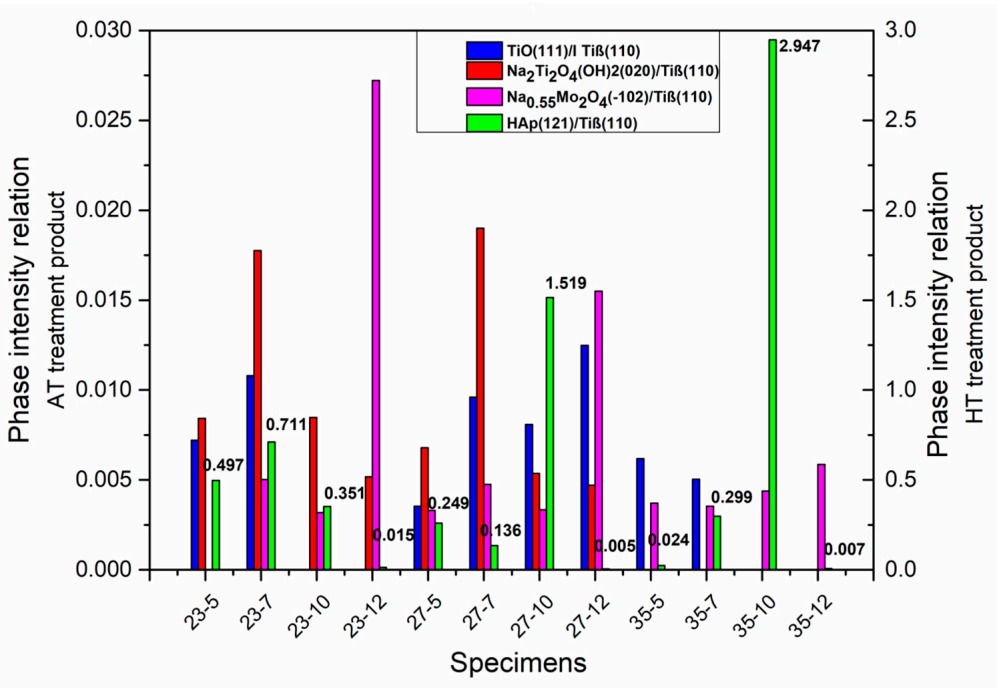

Figure 14. The intensity pairs of the products phase relation values collated in changeable substrate composition and AT treatment solution concentration.

\subsection{Wettability Tests}

The properties of the surface, including its hydrophilicity or hydrophobicity, have a significant influence on the interaction between the surface of the biomaterial and the biological environment, in particular, on the number of adsorbed proteins and their adhesion to the surface. In biomedical applications, a desirable situation is defined by a material that exhibits hydrophilic surface properties. The abovementioned properties have a positive effect on the adsorption, adhesion, and cell proliferation activity, which remain important in osseointegration characteristics improvement.

Selected HAp layers on TixMo alloys have been characterized in terms of wettability by glycerol testing fluid presented in Figure 15. All modified sample surfaces possess high hydrophilicity. The contact angle (CA) in time when the drop was placed $(t=0)$ was $30^{\circ}, 26^{\circ}$, and $31.5^{\circ}$ for $23-10 \mathrm{HT}$, $27-10 \mathrm{HT}$, and 35-10HT, respectively. In the case of 23-10HT after $4.5 \mathrm{~s}$ the CA decreased to approximately $7.5^{\circ}$, the same effect was achieved after $6.5 \mathrm{~s}$ for $27-10 \mathrm{HT}$ and 35-10HT. Additionally, the unmodified surfaces of Ti-xMo alloys and microcrystalline titanium were analyzed for comparison purposes. The HT confirms a visible CA decrease for selected covered samples in comparison to untreated samples.

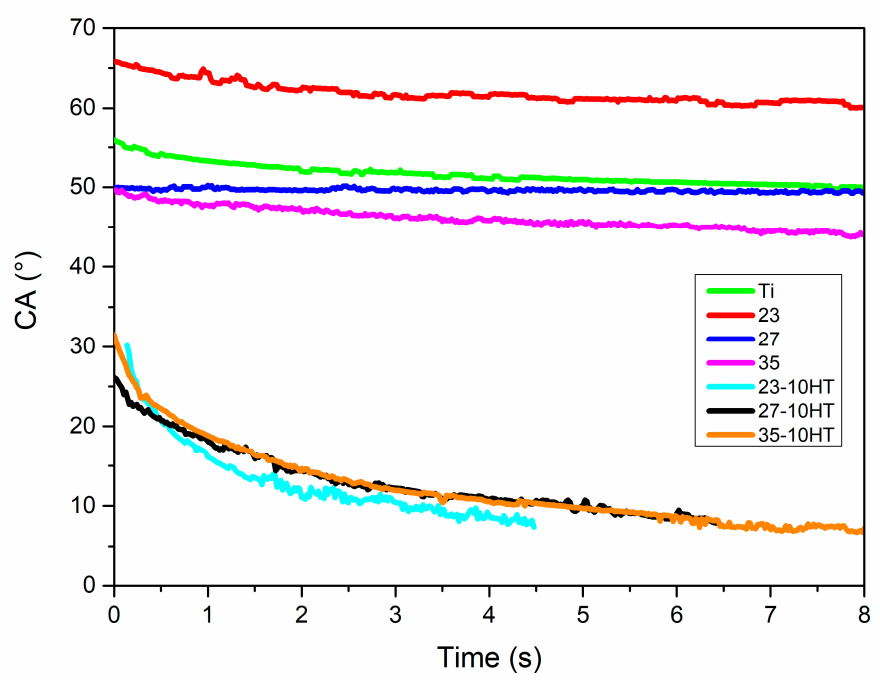

Figure 15. A glycerol contact angle relation for 23-10HT, 27-10HT, 35-10HT, Ti23Mo, Ti27Mo, and Ti35Mo samples in a time function. 


\section{Conclusions}

The authors proposed a schematic course of the process presented in Figure 16. The attention should be focused on the substrate composition, structure, size, morphology, homogeneity, and physiochemical properties that follow, influencing HAp layer state and final properties through the intermediate alkaline treatment, that mimics the substrate.

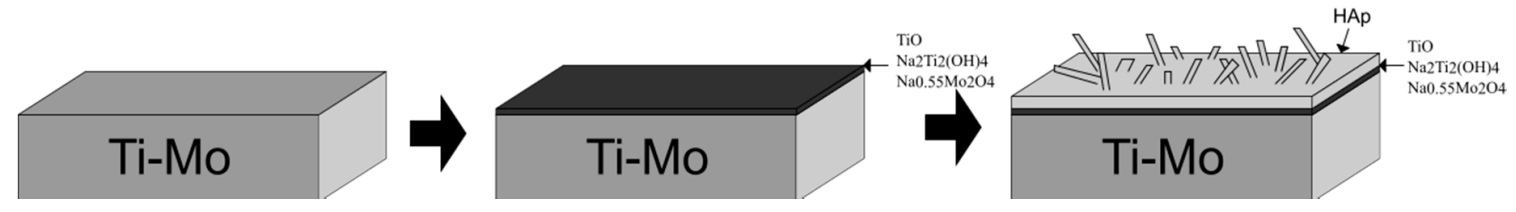

Figure 16. The schematic presentation of HAp formation on TixMo specimens.

The obtained in this work results indicate that the proposed process enables the preparation of a hydroxyapatite coating. However, the HAp layer is the most developed for samples treated with alkaline treatment in $7 \mathrm{M}$ and $10 \mathrm{M} \mathrm{NaOH}$ solution. The above statement confirms also stable intermediate phase forms obtained on the substrates after AT, necessary as Figure 16 shows for HAp layer formation and growth.

The sample comparison in terms of starting chemical composition does not reveal any significant differences between the resulting coatings for the samples after treatment with $7 \mathrm{M}$ and $10 \mathrm{M} \mathrm{NaOH}$. The differences are noticeable only for the samples after treatment with $12 \mathrm{M} \mathrm{NaOH}$, the least developed coating was obtained for the Ti27Mo $12 \mathrm{M}$ sample. Coatings on Ti23Mo $12 \mathrm{M}$ and Ti35Mo $12 \mathrm{M}$ samples have similar characteristics and island-like morphology. Furthermore, conducted research confirms the positive effect of the obtained HAp layers on the wettability surface characteristics in the time managed tests.

The obtained results prove that a proper process control allows overcoming mentioned problems for other technological approaches of HAp deposition, also in large scale and complex parts geometry at a low demandable approach. The hydrothermal treatment approach remains to grow in interest by the research community, and in the future, we hope by its simplicity, also by the manufacturers. Conducted research remains also the first step in further consideration and field recognition in a possible adaptation of low-temperature hydrothermal processing in the drug encapsulation and delivery systems.

Author Contributions: Conceptualization, D.P. and A.M.; Data curation, D.P. and A.M.; Formal analysis, A.M.; Funding acquisition, A.M.; Investigation, D.P. and A.M.; Methodology, A.M.; Project administration, M.J.; Supervision, A.M. and M.J.; Visualization, D.P.; Writing—original draft, D.P. and A.M.; Writing—review \& editing, A.M. All authors have read and agreed to the published version of the manuscript.

Funding: The work has been financed by the National Science Centre Poland under decision no.: DEC-2017/25/B/ST8/02494.

Acknowledgments: A.M. and M.J. acknowledge the financial support of the National Science Centre Poland under decision no.: DEC-2017/25/B/ST8/02494. D.P. acknowledges the financial support of the Polish Ministry of Science and Higher Education (Project No. 0513/SBAD/4606).

Conflicts of Interest: The authors declare no conflict of interest. The funders had no role in the design of the study; in the collection, analyses, or interpretation of data; in the writing of the manuscript, or in the decision to publish the results.

\section{References}

1. Geetha, M.; Singh, A.K.; Asokamani, R.; Gogia, A.K. Ti based biomaterials, the ultimate choice for orthopaedic implants-A review Ti based biomaterials, the ultimate choice for orthopaedic implants-A review. Prog. Mater. Sci. 2009, 54, 397-425. [CrossRef]

2. Niinomi, M. Mechanical properties of biomedical titanium alloys. Mater. Sci. Eng. A 1998. [CrossRef] 
3. Li, Y.; Yang, C.; Zhao, H.; Qu, S.; Li, X.; Li, Y. New Developments of Ti-Based Alloys for Biomedical Applications. Materials 2014, 7, 1709-1800. [CrossRef]

4. Marczewski, M.; Miklaszewski, A.; Jurczyk, M. Structure evolution analysis in ultrafine-grained Zr and Nb-based beta titanium alloys. J. Alloys Compd. 2018, 765, 459-469. [CrossRef]

5. Sochacka, P.; Miklaszewski, A.; Jurczyk, M. Development of b -type Ti-x at. \% Mo alloys by mechanical alloying and powder metallurgy: Phase evolution and mechanical properties. J. Alloys Compd. 2019, 776, 370-378. [CrossRef]

6. Zhang, Y.; Chu, K.; He, S.; Wang, B.; Zhu, W.; Ren, F. Materials Science \& Engineering C Fabrication of high strength, antibacterial and biocompatible Ti-5Mo-5Ag alloy for medical and surgical implant applications. Mater. Sci. Eng. C 2020, 106, 110165.

7. Sochacka, P.; Miklaszewski, A.; Jurczyk, M. The influence of mo content on phase transformation in Ti-Mo alloys. Arch. Metall. Mater. 2017, 62, 2051-2056. [CrossRef]

8. Mareci, D.; Solcan, C.; Mircea, F.; Carmen, L.; Fern, L. New Ti-6Al-2Nb-2Ta-1Mo alloy as implant biomaterial: In vitro corrosion and in vivo osseointegration evaluations. Mater. Chem. Phys. 2020, 240, 1-10. [CrossRef]

9. Correa, D.R.N.; Vicente, F.B.; Araújo, R.O.; Lourenço, M.L.; Kuroda, P.A.B.; Buzalaf, M.A.R.; Grandini, C.R. Effect of the substitutional elements on the microstructure of the Ti-15Mo-Zr and Ti-15Zr-Mo systems alloys. J. Mater. Res. Technol. 2015. [CrossRef]

10. Martins, J.R.S., Jr.; Araujo, R.O.; Nogueira, R.A.; Grandini, C.R. Internal friction and microstructure of Ti and Ti-Mo alloys containing oxygen. Arch. Metall. Mater. 2016, 61, 25-30. [CrossRef]

11. Zhang, W.; Liu, Y.; Wu, H.; Song, M.; Zhang, T.; Lan, X.; Yao, T. Materials Characterization Elastic modulus of phases in Ti-Mo alloys. Mater. Charact. 2015, 106, 302-307. [CrossRef]

12. Cardoso, F.F.; Ferrandini, P.L.; Lopes, E.S.N.; Cremasco, A.; Caram, R. Ti-Mo alloys employed as biomaterials: Effects of composition and aging heat treatment on microstructure and mechanical behavior. J. Mech. Behav. Biomed. Mater. 2014. [CrossRef] [PubMed]

13. Zhang, L.; Webster, T.J. Nanotechnology and nanomaterials: Promises for improved tissue regeneration. Nano Today 2009. [CrossRef]

14. Mohseni, E.; Zalnezhad, E.; Bushroa, A.R. International Journal of Adhesion \& Adhesives Comparative investigation on the adhesion of hydroxyapatite coating on Ti-6Al-4V implant: A review paper. Int. J. Adhes. Adhes. 2014, 48, 238-257.

15. Neves, G.A. A brief review on hydroxyapatite production and use in biomedicine. Ceramica 2019, 65, $282-302$.

16. Zhou, H.; Lee, J. Nanoscale hydroxyapatite particles for bone tissue engineering. Acta Biomater. 2011, 7, 2769-2781. [CrossRef]

17. Koutsopoulos, S. Kinetic Study on the Crystal Growth of Hydroxyapatite. Langmuir 2001, 17, $8092-8097$. [CrossRef]

18. Haider, A.; Gupta, K.C.; Kang, I.K. PLGA/nHA hybrid nanofiber scaffold as a nanocargo carrier of insulin for accelerating bone tissue regeneration. Nanoscale Res. Lett. 2014, 9, 1-12. [CrossRef]

19. Gadow, R.; Killinger, A.; Stiegler, N. Hydroxyapatite coatings for biomedical applications deposited by different thermal spray techniques. Surf. Coatings Technol. 2010. [CrossRef]

20. Cüneyt Tas, A. Synthesis of biomimetic Ca-hydroxyapatite powders at $37^{\circ} \mathrm{C}$ in synthetic body fluids. Biomaterials 2000, 21, 1429-1438. [CrossRef]

21. Sygnatowicz, M.; Tiwari, A. Controlled synthesis of hydroxyapatite-based coatings for biomedical application. Mater. Sci. Eng. C 2009, 29, 1071-1076. [CrossRef]

22. Cui, F.Z.; Luo, Z.S.; Feng, Q.L. Highly adhesive hydroxyapatite coatings on titanium alloy formed by ion beam assisted deposition. J. Mater. Sci. Mater. Med. 1997, 8, 403-405. [CrossRef] [PubMed]

23. Choi, J.M.; Kim, H.E.; Lee, I.S. Ion-beam-assisted deposition (IBAD) of hydroxyapatite coating layer on Ti-based metal substrate. Biomaterials 2000, 21, 469-473. [CrossRef]

24. Gross, K.A.; Chai, C.S.; Kannangara, G.S.K.; Ben-Nissan, B.; Hanley, L. Thin hydroxyapatite coatings via sol-gel synthesis. J. Mater. Sci. Mater. Med. 1998, 9, 839-843. [CrossRef]

25. Hu, X.; Shen, H.; Cheng, Y.; Xiong, X.; Wang, S.; Fang, J.; Wei, S. One-step modification of nano-hydroxyapatite coating on titanium surface by hydrothermal method. Surf. Coatings Technol. 2010, 205, 2000-2006. [CrossRef]

26. Faghihi-Sani, M.A.; Arbabi, A.; Mehdinezhad-Roshan, A. Crystallization of hydroxyapatite during hydrothermal treatment on amorphous calcium phosphate layer coated by PEO technique. Ceram. Int. 2013, 39, 1793-1798. [CrossRef] 
27. Kim, C.; Kendall, M.R.; Miller, M.A.; Long, C.L.; Larson, P.R.; Humphrey, M.B.; Madden, A.S.; Tas, A.C. Comparison of titanium soaked in $5 \mathrm{M} \mathrm{NaOH}$ or $5 \mathrm{M} \mathrm{KOH}$ solutions. Mater. Sci. Eng. C 2013, 33, 327-339. [CrossRef]

28. Hsu, H.; Wu, S.; Hsu, S.; Hsu, C.; Ho, W. Bone-like nano-hydroxyapatite coating on low-modulus Ti-5Nb-5Mo alloy using hydrothermal and post-heat treatments. Thin Solid Films 2019, 687, 137463. [CrossRef]

29. Baddeley, M. Material Fundamentals and Clinical Performance of Plasma-Sprayed Hydroxyapatite Coatings: A Review. Keynes Post Keynes. Polit. Econ. 1999, 570-592.

30. Song, H.J.; Kim, J.W.; Kook, M.S.; Moon, W.J.; Park, Y.J. Fabrication of hydroxyapatite and TiO 2 nanorods on microarc-oxidized titanium surface using hydrothermal treatment. Appl. Surf. Sci. 2010, 256, 7056-7061. [CrossRef]

31. Titanium, P. Characterization of Nano-Scale Hydroxyapatite Coating Synthesized from Eggshells Through Hydrothermal Reaction on Commercially Pure Titanium. Coatings 2020, 10, 112.

32. Suchanek, K.; Bartkowiak, A.; Gdowik, A.; Perzanowski, M.; Kąc, S.; Szaraniec, B.; Suchanek, M.; Marszałek, M. Crystalline hydroxyapatite coatings synthesized under hydrothermal conditions on modified titanium substrates. Mater. Sci. Eng. C 2015, 51, 57-63. [CrossRef] [PubMed]

33. Ho, W.-F.; Lai, C.-H.; Hsu, H.-C.; Wu, S.-C. Surface modification of a low-modulus Ti-7.5Mo alloy treated with aqueous $\mathrm{NaOH}$. Surf. Coat. Technol. 2009, 203, 3142-3150. [CrossRef]

34. Abdal-hay, A.; Salam Hamdy, A.; Khalil, K.A.; Lim, J.H. A novel simple one-step air jet spinning approach for deposition of poly(vinyl acetate)/hydroxyapatite composite nanofibers on Ti implants. Mater. Sci. Eng. C 2015, 49, 681-690. [CrossRef]

35. Sadat-Shojai, M.; Khorasani, M.-T.; Dinpanah-Khoshdargi, E.; Jamshidi, A. Synthesis methods for nanosized hydroxyapatite with diverse structures. Acta Biomater. 2013, 9, 7591-7621. [CrossRef]

36. Arce, H.; Montero, M.L.; Aenz, A.S.; Casta, V.M. Effect of pH and temperature on the formation of hydroxyapatite at low temperatures by decomposition of a Ca-EDTA complex. Polyhedron 2004, 23, 1897-1901. [CrossRef]

37. Lak, A.; Mazloumi, M.; Mohajerani, M.; Kajbafvala, A.; Zanganeh, S.; Arami, H.; Sadrnezhaad, S.K. Self-assembly of dandelion-like hydroxyapatite nanostructures via hydrothermal method. J. Am. Ceram. Soc. 2008, 91, 3292-3297. [CrossRef]

38. Hench, L.L. Bioceramics: From concept to clinic. J. Am. Ceram. Soc. 1991, 74, 1487-1510. [CrossRef]

Publisher's Note: MDPI stays neutral with regard to jurisdictional claims in published maps and institutional affiliations.

(C) 2020 by the authors. Licensee MDPI, Basel, Switzerland. This article is an open access article distributed under the terms and conditions of the Creative Commons Attribution (CC BY) license (http://creativecommons.org/licenses/by/4.0/). 